\title{
Missing the link: urban stormwater quality and resident behaviour
}

\author{
EW Ward ${ }^{1 *}$ and K Winter ${ }^{1}$ \\ 'Department of Environmental and Geographical Science, University of Cape Town, Private Bag X3, Rondebosch 7701, South Africa
}

\begin{abstract}
Conventional urban drainage systems are designed to reinforce human dominance over the biophysical environment resulting in contaminated surface runoff being discharged into urban waterways. It is widely recognized that poor stormwater quality is one of the main contributing factors to the deterioration of urban rivers. The result is that bluegreen corridors of urban open spaces are compromised by the cumulative impacts of pollution that alter productive ecosystem services and are no longer able to support biodiversity. The problem is partly caused by conventional stormwater infrastructure, which is designed to remove runoff as quickly and efficiently as possible. Yet the condition of an urban waterway cannot be understood simply as a cause and effect relationship, but emerges from interactions between people, drainage and ecological systems. This study aimed to understand the linkage between biophysical and social systems in an urban setting in Cape Town, South Africa. Surface water flowing into roadside catchpits was analysed using multiple water quality parameters. Surveys, interviews and observations explored how local residents understand their impacts on the quality of an urban river. The results show that runoff is highly variable and some environmental conditions, such as rainfall, antecedent dry days and season, are the primary drivers of water quality. However, residents have a poor understanding of the linkages between what they do on the land and impacts on urban rivers. The findings suggest that the predominant focus on technological solutions and flood prevention do not persuade citizens to account for actions that result in deterioration of waterway conditions. Drainage infrastructure fails to connect citizens with their downstream impacts on environmental systems and services. The implication is that most residents 'miss the link' - between their actions on land, their impacts on runoff and river water quality, and, in turn, their ability to influence societal patterns and processes.
\end{abstract}

Keywords: stormwater drainage, social-ecological systems, environmental impacts, human behaviour, urban ecology

\section{INTRODUCTION}

Cities are functional ecosystems governed by interacting social and ecological patterns and processes (Grimm et al., 2000). Yet urban design and infrastructure have a strong tendency to disconnect residents from natural processes and obscure the inherent relationships between societal and ecological conditions (Wong and Eadie, 2000; Selman et al., 2010). It is not surprising therefore that ecological degradation and a limited diversity of species are pervasive in urban rivers and wetlands. Apart from the impact of poorly-treated wastewater being discharged into urban river systems - an extensive problem in South Africa - it is now widely acknowledged that conventionally managed stormwater significantly contributes to the deterioration of surface water quality (Glazewski, 2005; Konrad and Booth, 2005).

Conventional stormwater management is designed to address flooding and public safety risks by removing runoff as quickly and efficiently as possible (Butler and Davies, 2011). These management objectives often overshadow environmental concerns and the complexity of social-ecological systems, resulting in poor water quality and degraded urban rivers (Walsh et al., 2005; Butler and Davies, 2011).

The condition of an urban waterway is the result of dynamic interactions between people, technology, and ecological systems (Paul and Meyer, 2001; Konrad and Booth, 2005; Walsh et al., 2005). Generally these interactions are poorly understood because there is a paucity of research in urban stormwater management that focuses on the integration of societal patterns

\footnotetext{
* To whom all correspondence should be addressed.

ฮ +27 72191 8638; e-mail: elward28@gmail.com

Received 29 November 2015; accepted in revised form 6 September 2016
}

and processes that interact with both technology and ecological systems (Wong and Eadie, 2000; Pahl-Wostl et al., 2007).

While South Africa has progressive water policies, local authorities continue to use conventional techniques and infrastructure in stormwater management. Some researchers argue that management strategies and policies that ignore interactions between ecology and society are unable to produce sustainable outcomes (Pickett et al., 1997; Alberti et al., 2008).

The aim of this study was to examine simultaneous interconnections of stormwater drainage systems, runoff quality, and resident knowledge and experience. The study sought to understand the potential to conceptually link actions on the land with existing drainage technology and applies the Urban Ecology model described by Grimm et al. (2000) to develop a new perspective on conventional urban stormwater and the social system in which it is embedded.

\section{The Urban Ecology model}

The Urban Ecology model views societal and ecological patterns and processes as inherently linked (Grimm et al., 2000; Collins et al., 2011). It accounts for the dynamic interactions, feedbacks, and linkages between biophysical variables (e.g. climate, geologic context, and natural cycles) and the individual decisions of various human actors (e.g. government, planners, businesses, and households) (Collins et al., 2011). The model (Fig. 1) illustrates how environmental contexts (e.g. climate and watershed dynamics) and social processes (e.g. policy or management) inform and constrain land use and land use change (see processes 'A' and 'B' in Fig. 1) (Grimm et al., 2000). It suggests that environmental patterns and processes are enhanced or impaired due to feedbacks from land use or management decisions (processes ' $\mathrm{C}$, ' $\mathrm{F}$, 
and (I'). The current state of an ecological system, land use, or changes therein, can influence the perceptions of individuals towards that ecosystem and its management (through processes 'D', 'E', and 'G'), with the potential to feed back to and influence societal patterns and processes ('H'). In turn, society can respond directly to undesirable changes in ecological conditions (' $J$ ') or can respond to the mechanisms causing those changes (' $\mathrm{K}$ ').

Interactions within this model illustrate a sequence of phases, where 'land use' and 'ecological patterns and processes' are a snapshot of a single point in time. When a change occurs in these conditions or environmental problems arise, a sequence of interactions and feedbacks follow, which could include solutions or adjustments in management decisions and operations. In a transition toward more sustainable urban water management, the linkage represented by ' $\mathrm{H}$ ' is a potentially valuable tool, whereby changes in perceptions or attitudes towards a land use, ecological patterns, or altered ecological conditions can influence societal patterns and processes towards re-evaluating ecological systems and regenerating environmental services offered within urban waterways.

\section{South Africa: management of urban surface runoff}

South Africa is a water-scarce country facing increasing pressures from population growth and urbanization. The majority (57\%) of river ecosystems are threatened: $23 \%$ critically endangered, 19\% endangered, and 13\% vulnerable (Driver et al., 2012). Surface water pollution is a serious and growing problem, which is exacerbated by the loss of natural riparian vegetation (ibid.). Changes in urban surface hydrology and deteriorating water quality are fundamentally connected to stormwater runoff from urban areas (River Health Programme, 2005; Driver et al., 2012). Although South Africa has a sophisticated legislative system in place to protect its scarce water resources, aquatic ecosystems continue to be degraded (Brown and Magoba, 2009; Driver et al., 2012). Pollution from urban runoff was identified by the national Department of Water and Sanitation (then the Department of Water Affairs and Forestry) as one of the three main problems for national water resources (Glazewski, 2005).

\section{Urban rivers of Cape Town}

Cape Town has a Mediterranean climate with warm dry summers and mild wet winters, and thus seasonally-influenced river systems. Average rainfall is $764 \mathrm{~mm} / \mathrm{a}$ with 56 million $\mathrm{m}^{3}$ of annual runoff (River Health Programme, 2005). Most of the rivers of the Greater Cape Town area transect densely populated urban areas. Consequently, Cape Town's rivers carry water of very poor quality, especially in their middle and lower reaches (ibid.). Over 20.4 million ZAR was spent in 2007 alone on river and wetland restoration and maintenance by various organizations in Cape Town (Brown and Magoba, 2009). Approximately two-thirds of this was allocated for problems created by urbanization and externalities exacerbated by technological solutions to water drainage problems.

\section{METHODS}

Research activities were conducted at two locations in the Liesbeek catchment, a sub-catchment of the Salt River in the City of Cape Town, during the winter rainfall period of 2012. Both locations are within suburbs of Cape Town, namely Observatory and Newlands, and are formal urban areas dominated by

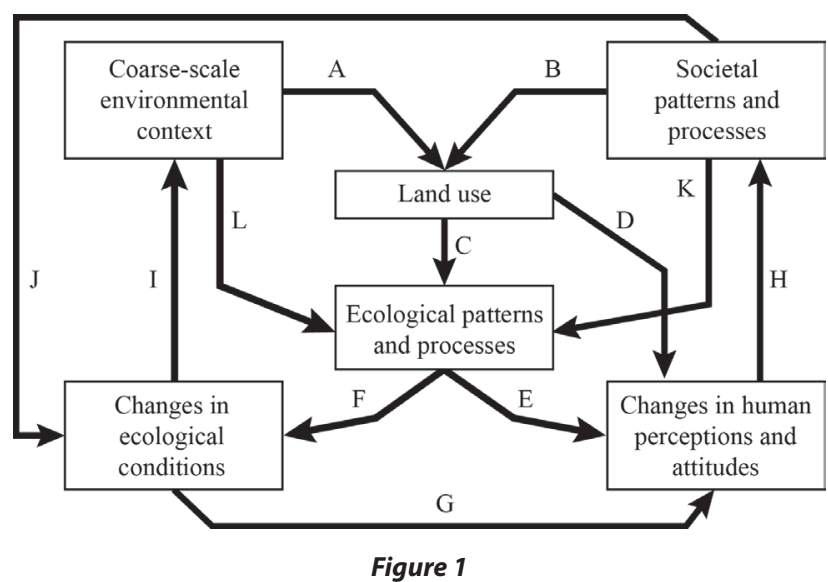

The Urban Ecology model, illustrating the integration of societal and ecological processes that influence conditions in the urban landscape (Grimm et al., 2000)

residential development and infrastructure. These locations were selected because of their varied residential development densities and impervious surface coverage, similar socio-economic and education status, relatively low level of commuter traffic, and close proximity and drainage connection to the Liesbeek River. Newlands is a well-established upmarket area, while Observatory is an upper-mid-market area. Observatory has higher residential density ( 8.77 vs. $5.86 \mathrm{hh} / \mathrm{ha}$ ) and greater impervious surface coverage (69.64\% vs. $42.50 \%$ ) compared to Newlands (City of Cape Town, 2013). Observatory residents vary from low to upper income (75.9\% earn below $25601 \mathrm{ZAR} /$ month), while Newlands residents tend towards middle and upper income levels (52.4\% earn 25601 ZAR and above per month) (ibid.).

\section{Water quality}

Water quality analyses were used to describe the 'ecological patterns and processes' highlighted in the Urban Ecology model (Fig. 1). Samples were collected and analysed to determine the quality of stormwater entering the drainage catchpits during storm events of varying rainfall intensity. Catchpits selected for sample collection had a similar structural design and were chosen to obtain a relatively even distribution over the study area, comprising approximately $30 \%$ of the total number of area catchpits.

Water quality sampling was conducted from July to October of 2012 for storm events that resulted in greater than $4.0 \mathrm{~mm}$ of rainfall, a cut-off below which insufficient runoff samples were generated. Sampling containers were installed on the upslope side of stormwater catchpits and emptied following each storm event. A total of 25 catchpit locations were analysed in Newlands (13) and Observatory (12) over 24 storm events. On-site measurements of temperature $\left({ }^{\circ} \mathrm{C}\right), \mathrm{pH}$, and TDS $(\mathrm{mg} / \mathrm{L})$ were performed using handheld digital instruments. Analyses to determine concentrations of orthophosphate $\left(\mathrm{PO}_{4}^{3-}\right)$, ammonia $\left(\mathrm{NH}_{3}^{-}\right)$, nitrate $\left(\mathrm{NO}_{3}^{-}\right)$, and nitrite $\left(\mathrm{NO}_{2}^{-}\right)$were conducted at the Water Analysis Laboratory of the University of Cape Town.

\section{Residential survey design}

A survey of local residents in each study area was designed to obtain information about residents' knowledge and experience of the local stormwater drainage system. The survey began with questions that examined their respective views of the Liesbeek River and sources of pollution in urban waterways. Residents 
were asked about their outdoor activities, such as the use of fertilizers and pesticides, garden irrigation, pet waste management, and vehicle washing. The survey examined knowledge of the stormwater drainage system design and infrastructure, and any issues encountered in its function and use. Questions were designed to illuminate conceptual linkages between actions, stormwater and river health. Surveys were administered in late August 2012 and continued until early February 2013.

\section{RESULTS and DISCUSSION}

\section{Water quality}

A total of 600 water quality samples were collected throughout the sampling period (312 were in the Newlands study area and 288 in the Observatory study area). Mixed effect regression analysis was performed to understand the relationships between water quality and explanatory variables. It was expected that water quality parameters would be variably influenced by rainfall, antecedent dry period, location, and season.

Models were built using all subsets. The preferred model was determined by comparing the adjusted Aikaike's and Bayesian Information Criteria (AIC and BIC, respectively). Once the model was selected, the $p$-value was used to determine whether an explanatory variable was significant at the $5 \%$ or $10 \%$ level. Fixed effect variables investigated include antecedent dry days (the number of preceding days when rainfall $\leq 4 \mathrm{~mm}$ in the $24 \mathrm{~h}$ period), rainfall ( $\mathrm{mm}$, determined with 2 rain gauges per study area), season (spring verses winter), and area (Newlands versus Observatory). Table 1 presents the variables included in regression models.

The results show that stormwater quality is highly variable, both spatially (across individual catchpit locations) and temporally. Table 2 presents a summary of the water quality parameter trends for the multiple explanatory variables.

All parameters except $\mathrm{NO}_{3}{ }^{-}$were significantly influenced by rainfall, indicating that rainfall volume is a primary driver of contaminant loading and water quality. An increase from the centred average rainfall led to a decrease in TDS, $\mathrm{PO}_{4}^{3-}, \mathrm{NH}_{3}^{-}$, and $\mathrm{NO}_{2}^{-}$concentrations. This is consistent with the 'first flush' theory, whereby contaminant concentrations decrease with increasing rainfall as surfaces are washed clean and loads are diluted (Mulliss et al., 1996; Bertrand-Krajewski et al., 1998; Lee et al., 2002).

With the exception of $\mathrm{NO}_{3}$, all water quality parameters examined in this study were significantly influenced by the duration of the antecedent dry weather period. TDS, $\mathrm{PO}_{4}^{3-}$, and $\mathrm{NH}_{3}{ }^{-}$concentrations increased with increasing dry weather days, indicating that an increased dry weather period allows contaminants to build up on surfaces. $\mathrm{PO}_{4}^{3-}, \mathrm{NH}_{3}$, and $\mathrm{NO}_{2}{ }^{-}$concentrations were all significantly higher in spring than in winter months. This may be related to local activities, which can directly influence pollutant availability through direct contamination of the surface area (Pitt et al., 1995). For example, residential lawns and gardens are common sources of nutrients and pesticides (Paul and Meyer, 2001). Resident surveys revealed that 69.39\% of residents who apply fertilizers do so in the spring, while only $4.08 \%$ apply fertilizer during the winter. Therefore, the observed increases in contaminant loads may partially be explained by an increase in fertilizer application by residents in the area.

\section{Results from resident survey}

During the survey period of August 2012 through February 2013, a total of 366 households were approached, comprising

\begin{tabular}{|c|l|l|}
\hline \multicolumn{3}{|c|}{ Variables used in mixed effect regression analyses } \\
\hline Representation & \multicolumn{1}{|c|}{ Variable } & \multicolumn{1}{c|}{ Description } \\
\hline$D$ & Antecedent dry days & The number of preceding days when rainfall $\leq 4 \mathrm{~mm}$ in the $24 \mathrm{~h}$ period \\
\hline$R$ & Centred average rainfall & Determined with 2 rain gauges per study area $(\mathrm{mm})$, where the mean is $23.3 \mathrm{~mm}$ \\
\hline$S$ & Season & Spring versus winter, where winter is used as the baseline \\
\hline$A$ & Area & Newlands versus Observatory, where Observatory is used as the baseline \\
\hline$C_{x}$ & Coefficient of variable $x$ & Where $x$ represents $D, R, S$, or $A$ \\
\hline$I$ & Intercept & The constant when all explanatory variables are null $(D, R, S, A=0)$ \\
\hline$u_{\mathrm{j}}$ & Random effect between locations & Where $j$ represents the individual location: the constant random effect \\
\hline$e_{i j}$ & Random effect within location & Where $i$ refers to observations within the location: the residual random effect \\
\hline Example & $L n(\text { dependent variable })_{i j}=D C_{D}+R C_{\mathrm{R}}+S C_{\mathrm{S}}+A C_{\mathrm{A}}+I+u_{\mathrm{j}}+e_{\mathrm{ij}}$ \\
\hline
\end{tabular}

${ }^{*}$ Season effects are calculated by categorising data samples between July through August as winter, and September through October as spring

TABLE 2

Summary of water quality trends

\begin{tabular}{|c|c|c|c|c|c|}
\hline & $\begin{array}{c}\text { Antecedent Dry days } \\
\text { (D) }\end{array}$ & Rainfall $(R)$ & Season (S) & Area $(A)$ & Intercept \\
\hline & $\begin{array}{l}\text { (\% change per increase } \\
\text { of } 1 \text { day) }\end{array}$ & $\begin{array}{l}\text { (\% change per increase } \\
\text { of } 1 \mathrm{~mm})^{*}\end{array}$ & $\begin{array}{l}\text { (\% change in spring vs. } \\
\text { winter) }\end{array}$ & $\begin{array}{l}\text { (\% change in Newlands } \\
\text { vs. Observatory) }\end{array}$ & $\begin{array}{c}\text { (Value when } D, R, S, A \\
=0 \text { ) }\end{array}$ \\
\hline pH & -0.1 & +0.1 & +26 & $\mathrm{NA}$ & 8.34 \\
\hline TDS & +6.18 & -1.0 & NA & NA & $54.5982 \mathrm{mg} / \mathrm{L}$ \\
\hline $\mathrm{PO}_{4}{ }^{3-}$ & +8.33 & -1.0 & +89.65 & NA & $0.2783 \mathrm{mg} / \mathrm{L}$ \\
\hline NH3- & +10.52 & -1.0 & +46.23 & NA & $0.2408 \mathrm{mg} / \mathrm{L}$ \\
\hline $\mathrm{NO}_{3}^{-}$ & NA & NA & NA & -15.63 & $0.5066 \mathrm{mg} / \mathrm{L}$ \\
\hline $\mathrm{NO}_{2}^{-}$ & -3.92 & -1.0 & +37.71 & NA & $0.0072 \mathrm{mg} / \mathrm{L}$ \\
\hline
\end{tabular}

${ }^{*}$ Refers to centred average rainfall $(23.3 \mathrm{~mm})$ 
all 94 households in the Newlands study area and all 272 households in the Observatory study area. The participation rate was $18.58 \%$ culminating in a total of 68 completed surveys from the Newlands (32) and the Observatory (36) study areas. Most respondents claimed to have lived at their current address for at least 2 years $(86.76 \%)$, and over half $(54.41 \%)$ had been at their current address for 6 years or more.

Most respondents (95.59\%) believe stormwater management is primarily the responsibility of the local municipality, although $33.82 \%$ considered residents or property owners to hold secondary responsibility. Half of the respondents reported having experienced problems with stormwater drainage in the past; almost all of these were related to flooding $(94.12 \%)$. Some respondents call the local authority for support (20.59\%), but many take it upon themselves to address the problem (47.06\%), citing inadequate response by (or trust of) the municipality.

The survey results indicate that residents have a general knowledge of the stormwater system. Nearly all respondents $(91.18 \%)$ are aware that the stormwater system is separate from the sewerage system and the majority $(72.06 \%)$ understand that the water is discharged directly to the local river. Nearly a third of respondents believe that it is acceptable for some materials other than storm runoff to be disposed of through the stormwater system. These residents indicate that materials are acceptable as long as they are 'non-toxic' or 'not a pollutant'. (It is noted that making such a distinction would rely on the individual's knowledge of substances that would fall under this classification.)

The majority of respondents $(83.82 \%)$ indicate that they are concerned about the health of the Liesbeek River (51.47\% of which were 'very concerned'). The results suggest that there is a tendency for respondents to place blame for locally caused river pollution externally. For example, respondents view the primary and top three contributors to local pollution to include vagrants (36.76\%; 69.12\%), construction practices $(22.06 \% ; 50.0 \%)$ and non-residents (13.24\%; $52.95 \%)$. Only $10.29 \%$ reported residents as the primary contributor $(29.41 \%$ included residents in the top three contributors). There was also a tendency to identify highly visible pollutants as the main degrading contaminants. Litter and rubbish (58.82\%), illegal dumping (16.18\%), and building and construction waste $(11.76 \%)$ were the most commonly reported causes of local river pollution by respondents.

Less than half of respondents (47.37\%) who consider residential garden waste/runoff to be among the top five causes of local pollution also believe that residents are among the top five contributors to local pollution. This is similar to the findings of Norris and Burgin (2009), who reported that the majority of residents did not consider themselves as contributing to local stormwater pollution, with residents instead indicating that an intangible 'other' is at fault.

Activities reported by respondents indicate that they may have a more significant impact on stormwater quality than they currently perceive. Many respondents regularly apply fertilizers (72.06\%: 69.39\% in spring, 4.08\% in winter), discharge vehicle wash runoff $(80.0 \%)$ or pool backwash $(51.61 \%)$ into the street, and allow pet wastes to decompose outside (42.85\%). Although the effect of individual activities on stormwater quality was not examined in this study, water quality results showing higher nutrient levels in spring months appear to coincide with a period when most respondents apply fertilizers. Overall the results indicate that residents do not clearly understand how their actions on land are linked to water quality impacts or river conditions. 'Perceptions of impact are important because, whether right or wrong, they inform the decision-making of residents and professionals in selecting behaviours to target in campaigns (professionals) and whether or not to undertake them (residents)' (Ramkissoon et al., 2015, p. 3).

\section{CONCLUSIONS}

New insights are presented in an applied Urban Ecology model (Fig. 2) informed by this study. Some interconnections are represented as stronger (bold) or weaker (dashed) linkages, as described below.

Stormwater quality is highly variable over space and time. Some environmental conditions (rainfall, antecedent dry days, and season) were shown to be primary drivers of water quality, creating a strong linkage represented as 'L' in Fig. 2. Even with societal interventions such as litter grids, street sweeping, and clearing of the drainage inlets (process ' $\mathrm{K}$ '), debris and contaminants continue to enter the drainage systems and are discharged into the waterway (De Barros et al., 2014). The literature clearly shows that the current environmental context (e.g. catchment hardening and reduced infiltration capacity) strongly influences ecological patterns and processes through land use and management (i.e. conventional drainage techniques) (Arnold and Gibbons, 1996; Paul and Meyer, 2001; Konrad and Booth, 2005), indicating that processes ' $\mathrm{A}$ ' and ' $\mathrm{C}$ ' are strong linkages. Following these interactions, through process ' $\mathrm{F}$, it becomes evident that current approaches focusing on technological solutions and flood prevention do not meet the requirements for sustainable management of ecological conditions and environmental protection.

Although residents consider stormwater management to be primarily the responsibility of the local municipality, they appear reluctant to rely on these services. Reported problems of flooding, inadequate municipal maintenance, and misuse of the drainage system indicate that the expected societal benefits of these systems are not being fulfilled. The results suggest that residents perceive this shortcoming and are highly aware that efficient stormwater drainage is critical for flood avoidance and public safety, indicating a strong linkage represented as 'D'. Furthermore, residents exhibit a level of willingness to take partial responsibility for stormwater management. This willingness may be beneficial for the implementation of sustainable stormwater management techniques, such as those associated with the 'sustainable urban drainage systems' approach (Morison and Brown, 2011).

Consistent with the literature (Paul and Meyer, 2001; Butler and Davies, 2011), the results indicate that residential activity may have a significant influence on stormwater quality (process ' $\mathrm{K}$ '). However, the majority of residents may not perceive these impacts in the absence of highly visible effects. A weak understanding of the connection between certain activities and stormwater quality inhibits the ability of the public to interpret and respond to their own impacts on ecological patterns and processes ('E'). Although not examined in this study, the same is likely to be true for urban street litter, where a lack of environmental awareness leads to frequent clogging of drainage infrastructure (even with sufficient waste services) and amplifies municipal maintenance costs (De Barros et al., 2014).

While respondents reported being generally concerned with the health of the urban waterway, the results indicate a poor understanding of river conditions in relation to environmental and societal influences. The result is a weak linkage between changes in ecological conditions and changes in perceptions and attitudes ('G'). This is indicative of how, in the urban landscape, citizens are inclined to disregard the value and significance of urban stormwater because the infrastructure 


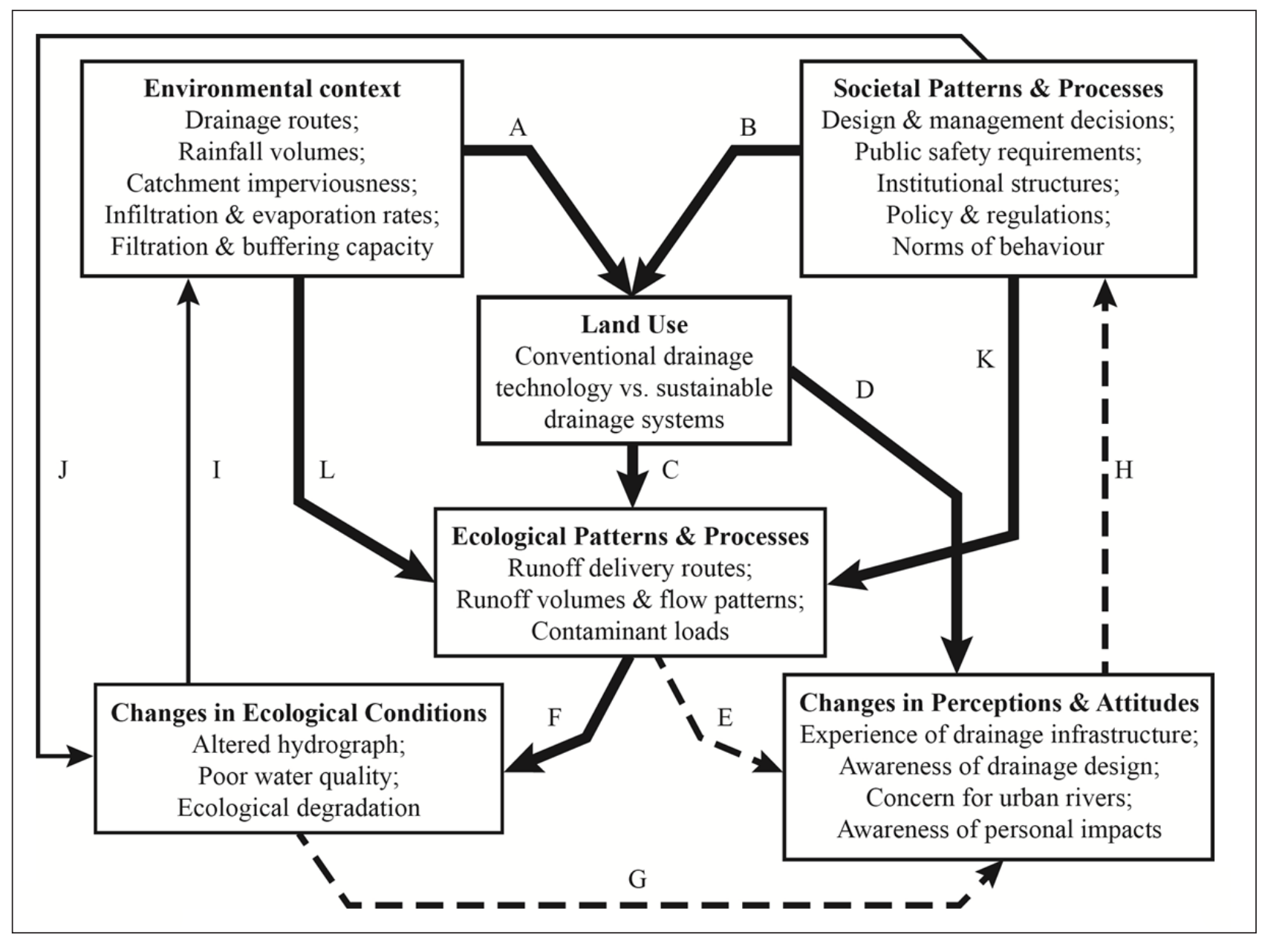

Figure 2

Study insights incorporated into an applied version of the Urban Ecology model

establishes structural and cognitive barriers between people and water systems, and contributes to the increasing dissociation between people and urban aquatic ecosystems (Stokman, 2008; Selman et al., 2010). Conventional drainage infrastructure, then, fails to connect citizens with their downstream impacts on ecological systems and environmental services, which inhibits the transition to water-sensitive cities.

The evolution towards a more sustainable urban ecosystem partially depends on society's ability to perceive and respond to changing needs and conditions in the built and natural environment (Brown et al., 2009). The public plays an important role in shaping these responses and adaptations (ibid.), however, the public influence on societal patterns and processes is likely to be hindered by a lack of awareness of stormwater system complexities. Therefore, inadequate awareness and poor communication with and trust of the municipality regarding system shortcomings weakens connection ' $\mathrm{H}$ ', and further inhibits the ability of residents and the municipality to progress towards a more desirable state, such as a more water-sensitive city. It is therefore apparent that conventional stormwater management lacks a mechanism that enables the public to conceptually link their actions on land with urban waterway conditions, which stifles the ability of residents to respond to changes and for management to achieve sustainable drainage, water quality and waterway health goals.

The overall effect illustrated in this applied Urban Ecology model is that most residents 'miss the link' - between their actions on land, their impacts on stormwater runoff and river water quality, and their ability to influence societal patterns and processes. Diffuse pollution from urban stormwater requires significantly more attention and resources in order to manage and reduce pollution in urban waterways and requires an integrated social-ecological perspective. The transition to sustainable drainage systems requires that people are not only connected to technology, but also with policy, planning, current available knowledge and the decision-making processes (Brown, 2005; Rauch et al., 2005; Pahl-Wostl et al., 2007; Wagner, 2008; Brown et al., 2009).

Targeted stormwater management techniques and improving public education and integration in institutional processes could improve the overall societal response to poor stormwater quality and degraded urban waterways. Haskins (2012) points out that the drivers of sustainable municipal stormwater strategies must be manifested in the form of goods and services, and management decisions must incorporate technical information (e.g. discharge, water quality, ecological conditions) that is balanced with considerations of socio-economic factors, and local needs and values. Understanding the local water culture and resulting behavioural patterns (that emerge from historical, geographical, and cultural contexts) can be used to develop a sequence of campaigns that seek to improve environmental awareness and shift behavioural patterns (Brown et al., 2009; Ramkissoon et al., 2015). 
On a broader scale, transitioning towards healthy urban waterways will require an overhaul of the conventional hydrosocial contract (Brown et al., 2009) and would represent the next major step in the applied Urban Ecology model, requiring significant changes in societal patterns and processes.

\section{ACKNOWLEDGEMENTS}

The researchers acknowledge funding support from the Water Research Commission for this study, which contributed to the project: 'South African Guidelines for Water Sensitive Settlements'. In addition, the researchers acknowledge the support of the University of Cape Town's Statistical Consulting Services in examining the data.

\section{REFERENCES}

ALBERTI M, MARZLUFF JM, SHULENBERGER E, BRADLEY G, RYAN C and ZUMBRUNNEN C (2008) Integrating humans into ecology: opportunities and challenges for studying urban ecosystems. BioScience 53 (12) 1169-1179.

ARNOLD C and GIBBONS C (1996) Impervious surface coverage: The emergence of a key environmental indicator. J. Am. Plann. Assoc. 62 (2) $243-258$.

BERTRAND-KRAJEWSKI J, CHEBBO G and SAGET A (1998) Distribution of pollutant mass vs volume in stormwater discharges and the first flush phenomenon. Water Res. 32 (8) 2341-2356.

BROWN C and MAGOBA R (2009) Rivers and Wetlands of Cape Town: Caring for our Rich Aquatic Heritage. Water Research Commission, Pretoria. 377 pp.

BROWN R (2005) Impediments to integrated urban stormwater management: the need for institutional reform. Environ. Manage. 36 (3) 455-468.

BROWN R, KEATH N and WONG T (2009) Urban water management in cities: historical, current and future regimes. Water Sci. Technol. 59 (5) 847-855.

BUTLER D and DAVIES JW (2011) Urban Drainage ( $3^{\text {rd }}$ edn). Spon Press, New York. 632 pp.

CITY OF CAPE TOWN (2013) Suburb profiles - 2011 census. City of Cape Town, Strategic Development Information \& GIS Department, Statistics South Africa. URL: https:/www.capetown.gov.za/en/stats/Pages/2011Census-Suburb-Profiles-land.aspx (Accessed 1 August 2013).

COLLINS SL, CARPENTER SR, SWINTON SM, ORENSTEIN DE, CHILDERS DL, GRAGSON TL, GRIMM NB, GROVE JM, HARLAN SL, KAYE JP and co-authors (2011) An integrated conceptual framework for long term social-ecological research. Front. Ecol. Environ. 9 (6) 351-357.

DE BARROS TR, MANCINI SD and FERRAZ JL (2014) Composition and quantification of the anthropogenic and natural fractions of wastes collected from the stormwater drainage system for discussions about the waste management and people behavior. Environ. Dev. Sustainability 16 (2) 415-429.

DRIVER A, SINK KJ, NEL JN, HOLNESS S, VAN NIEKERK L, DANIELS F, JONAS Z, MAJIEDT PA, HARRIS L and MAZE K (2012) National Biodiversity Assessment 2011: An Assessment of South Africa's Biodiversity and Ecosystems - Synthesis Report. South African National Biodiversity Institute and Department of Environmental Affairs, Pretoria. $200 \mathrm{pp}$.

GLAZEWSKI J (2005) Environmental Law in South Africa (2 ${ }^{\text {nd }}$ edn). LexisNexis Butterworths, Durban. 368 pp.
GRIMM NB, GROVE JM, PICKETT STA and REDMAN CL (2000) Integrated approaches to long-term studies of urban ecological systems. BioScience 50 (7) 571-584.

HASKINS CA (2012) Cape Town's sustainable approach to stormwater management. URL: http://www.capetown.gov.za/en/CSRM/Pages/ Reportsandscientificpapers.asx (Accessed 10 June 2012).

KONRAD CP and BOOTH DB (2005) Hydraulic changes in urban streams and their ecological significance. Am. Fish. Soc. Symp. 47 157-177.

LEE JH, BANG KW, KETCHUM LH, CHOE JS and YU MJ (2002) First flush analysis of urban storm runoff. Sci. Total Environ. 293 163-175.

MORISON P and BROWN R (2011) Understanding the nature of publics and local policy commitment to water sensitive urban design. Landscape Urban Plann. 99 (2) 83-92.

MULLISS R, REVITT D and SHUTES R (1996) The impacts of urban discharges on the hydrology and water quality of an urban watercourse. Sci. Total Environ. 190 385-390.

NORRIS A and BURGIN S (2009) Rhetoric and reality surrounding water quality issues in a peri-urban western Sydney community. Int. J. Environ. Stud. 66 (6) 773-783.

PAHL-WOSTL C, SENDZIMIR J, JEFFREY P, AERTS J, BERKAMP G and CROSS K (2007) Managing change toward adaptive water management through social learning. Ecol. Soc. 12 (2) 30.

PAUL M and MEYER J (2001) Streams in the urban landscape. Annu. Rev. Ecol. Syst. 32 333-365.

PICKETT STA, BURCH WR, DALTON SE, FORESMAN TW, GROVE JM and ROWNTREE R (1997) A conceptual framework for the study of human ecosystems in urban areas. Urban Ecosyst. 1 185-199.

PITT R, FIELD R, LALOR M and BROWN M (1995) Urban stormwater toxic pollutants: assessment, sources, and treatability. Water Environ. Res. 67 (3) 260-275.

RAMKISSOON H, SMITH L and KNEEBONE S (2015) Accelerating transition to water sensitive cities (Behaviour Assessment Database Report A2.2-1-2015). Cooperative Research Centre for Water Sensitive Cities, Melbourne. 77 pp.

RAUCH W, SEGGELKE K, BROWN R and KREBS P (2005) Integrated approaches in urban storm drainage: where do we stand? Environ. Manage. 35 (4) 396-409.

RIVER HEALTH PROGRAMME (2005) State of the Rivers Report: Greater Cape Town's rivers. URL: http://www.dwaf.gov.za/iwqs/rhp/ state_of_rivers.html (Accessed 12 June 2012).

SELMAN P, CARTER C, LAWRENCE A and MORGAN C (2010) Re-connecting with a neglected river through imaginative engagement. Ecol. Soc. 15 (3) 18.

STOKMAN A (2008) Water purificative landscapes - constructed ecologies and contemporary urbanism. In: Proceedings of the $45^{\text {th }}$ World Congress of the International Federation of Landscape Architects (IFLA), 30 June -3 July 2008, The Netherlands.

WAGNER M (2008) Acceptance by knowing? The social context of urban riparian buffers as a stormwater best management practice. Soc. Nat. Resour.. 21 (10) 908-920.

WALSH CJ, ROY AL, FEMINELLA JW, COTTINGHAM PD, GROFFMAN PM and MORGAN RP (2005) The urban stream syndrome: current knowledge and the search for a cure. J. N. Am. Benthol. Soc. 24 (3) 706-723.

WONG T and EADIE ML (2000) Water sensitive urban design - a paradigm shift in urban design. In: Proceedings of the $10^{\text {th }}$ World Water Congress. 12-16 March 2000, Melbourne. 